\title{
'THREE MONTHS' COLIC'
}

\author{
BY \\ R. S. ILLINGWORTH \\ From the Department of Child Health, The University of Sheffield and the Children's Hospital, Sheffield
}

(RECEIVED FOR PUBLICATION JANUARY 15, 1954)

In the first three months of life, rhythmic attacks of screaming, which are almost entirely confined to the evenings and cannot be explained by any of the known causes of crying, are a troublesome complaint which is familiar to all who are concerned with the care of well babies. It is commonly called 'three months' colic', because it gets better by the age of 3 months. For the sake of brevity I shall henceforward term it 'colic'.

This paper sets out to marshal the known facts about the condition, to discuss the theories as to its possible causes, and to present for comparison an analysis of data concerning 50 babies who suffered from it and 50 babies who did not.

\section{Description of the Condition}

The typical story is that of a baby aged between 3 days and 3 weeks who develops violent screaming attacks in the evenings, usually between 6 p.m. and 10 p.m. He behaves normally during the day, and sleeps well at night apart from demanding the usual night feed. In the attacks his face flushes, his brow furrows, and then he draws his legs up, clenches his fists and emits piercing, high-pitched screams, which do not stop when he is picked up, continuing unabated in his mother's arms. Each attack lasts five minutes or more. As the attack passes off he relaxes and stops screaming, and he is placed in his cot, obviously tired out. He is just about to go to sleep when another attack occurs. The attacks occur at regular intervals, with only a minute or two between them, until 10 p.m. or so, when he falls asleep and has no further trouble until the next evening.

During the attack it is commonly noted that there are unduly loud borborygmi. Some relief is usually given by placing him in the prone position, and he obtains considerable relief by passing flatus per rectum or by having a motion. Most babies obtain relief by sucking at the breast, but a few minutes afterwards the attacks begin again.

Mothers are very liable to take such a baby off the breast on the grounds that the breast milk is not suiting the baby, only to find that the complaint continues unabated when he is fed on cow's milk. They are apt to feed the baby almost constantly, because they ascribe the screaming to hunger, and he seems to obtain some relief from sucking. They are apt to offer him a bottle feed after or instead of a breast feed, only to find that he is no better or refuses it.

There are all gradations in the severity of this condition. Severe attacks cause a great deal of anxiety and alarm. In mild forms there is merely slight irritability in the evenings, the baby appearing to be 'uncomfortable', but apparently content as long as he is nursed. The description given above corresponds exactly with that given by Brennemann, $(1945,1948)$, Spock $(1944,1946)$, Keiter (1938), Levin (1950), Neff (1940), Copeland (1940) and others.

It is difficult to assess with accuracy the incidence of colic in well babies, because of the ease with which it can be confused with other conditions. In 100 consecutive well babies in the follow-up clinic at the Jessop Hospital at Sheffield I saw 21 whom I considered to be suffering from colic.* Jorup (1952) claimed that $30 \%$ of 589 children attending a child welfare centre in Stockholm had it, but his description does not conform in many important details with that given above. Rosamond (1921) remarked 'Every layman and every doctor with experience knows about three months' colic. It has happened in nearly every household.' Brennemann (1948) went further, and wrote that 'few babies escape it'. That I believe to be an exaggeration.

\section{Review of the Literature}

Considering the frequency and troublesome nature of evening colic, it is notable that comparatively few papers have been written on the subject. I could find no mention of it in three recent paediatric textbooks (Moncrieff and Evans, 1953; Fanconi and Wallgren, 1952; Ellis, 1951). A search of 49 volumes of the Quarterly Cumulative Index Medicus, and the 24 volumes of its predecessor, the Index Medicus, provided 38 references

* Subsequent observation in a larger number of babies has suggested that the figure is too high. 
to papers in various languages: all but two of these, which were unobtainable either here or in the United States, have been read in the preparation of this paper. All relevant papers have been included in the reference list at the end of this communication for the sake of others who are interested in the subject, but not all have been specifically referred to in the text, for the theories as to aetiology and treatment are so numerous that the insertion of references after each theory or suggested line of treatment would make this review quite unreadable.

Many writers suggest that there are several possible causes of colic. Higgins (1942), for instance, lists 20 causes. Several writers think that the cause is overfeeding. On the other hand Rosamond (1921) says that the cause is obviously underfeeding, and Keiter (1938) supports him. Several writers suggest that it can be due either to underfeeding or overfeeding, which seems to be contradictory. Some think that it is due to excessively frequent feeds, others to too infrequent feeds, and still more to either fault.

Most workers blame the constitution of the feeds on the ground that they are too rich, too weak, too hot, too cold, contain too much fat, too much carbohydrate or too much protein. Others (e.g., Miller, 1948) think that it is useless to change the feeds. Many workers ascribe colic to allergy, mostly to substances in milk, but possibly to substances in cod liver oil or orange juice. McCleave (1928) thought that it might be due to sensitivity to feathers or horsehair. White (1936) claimed that colic is as much a manifestation of allergy as infantile eczema, and described case histories in which the two coexisted, and cases in which colic was cured by removing the allergen by boiling the milk or using a milk substitute. His description of colic, however, does not conform with that given at the beginning of this paper, for the babies had extreme fretfulness aggravated by feeding, with projectile vomiting and usually diarrhoea, a condition which I have not seen. McGee $(1943,1950)$ agrees that colic is due to allergy, and claims that the probability that the baby will suffer from allergy can be detected while he is in utero, by the occurrence of foetal hiccoughs. He wrote that at least $50 \%$ of foetuses who had hiccough in utero had colic in early infancy as a result of allergy. I He wrote that other symptoms are usually associated with colic-nasal blockage or discharge, rattling sounds in the throat, excessive posseting or vomiting, mucus in the stools, constipation or diarrhoea, perianal irritation, nasal rubbing, papular rash on the face, and other troubles, some of them, one feels, being simply manifestations of the normal child. Shannon (1921a and b), Donnally (1930) and others have shown that certain proteins taken by the mother may pass into the milk and cause symptoms in the child. On the other hand Jorup (1952) and Hess (1940) thought that allergy was not the cause of colic.

A surprising number of writers claim that colic is associated with 'hypertonicity'. These writers include Haas (1918), Copeland (1940), Spitz (1951), Moore (1942), Higgins (1942), Neff (1940), Lippman (1928), Bonar (1935) and Miller (1948). The manifestations of hypertonicity given by these writers include such diverse signs and symptoms as an exaggerated Moro reflex, sharp response to sudden light, vigorous crying when having a bath, tenseness, excessive crying, wakefulness, pylorospasm, vomiting, spastic constipation, diarrhoea, abdominal distension, visible peristalsis, cardiospasm, tetany, overaction of the involuntary muscles, general spasticity or rigidity, the 'ability to support the body on the legs at 6 weeks', and to 'hold the head up almost from birth', the 'ability to grasp objects in the first few days of life', unusual alertness, pruritis ani, poor weight gain and many other conditions. Jorup (1952) describes similar symptoms in his cases. He was impressed by the 'neurolability' of colicky babies, the excessive sensitivity to sound and light, the shortness of their sleep, their general restlessness, their diarrhoea and their excessive sweating. Many other writers associate colic with diarrhoea (e.g., Grulee and Eley, 1948; White, 1929, 1936; McGee, 1950), while others claim that it is associated with constipation (Still, 1927; Current, 1920; McGee, 1950). White (1936) said that all but 40 cases seen by him were of the 'sthenic' or 'broad' type.

The parents have frequently been blamed for causing colic (Moore, 1942; Higgins, 1942; Keiter, 1938; Bonar, 1935; Neff, 1940). It is suggested that they cause colic by picking the baby up too much, by 'bouncing him too much after feeds in an effort to get the wind up', and communicating their nervousness and anxiety to him. Brennemann (1948) thought that colic was in some way connected with fatigue in the mother at the end of the day. Bonar (1935) thought that he could predict from the personality of the parents whether their babies were going to have colic. Spitz (1951) regarded colic as a combination of 'congenital hypertonicity' in the baby with 'primary anxious over-permissiveness' in the mother.

Several workers state that colic either never or very rarely occurs in the maternity unit, and only develops when the baby is taken home (Soto, 1937; Alarcon, 1951; Spock, 1944; Keiter, 1938; White, 1936; Pierce, 1948). Huenekens (1928) states that 
when a colicky baby is admitted to hospital the symptoms disappear. These workers ascribe the development of colic when the baby is taken home to mishandling, over-stimulation, excessive pickingup and over-anxiety. Hess (1940) suggested, however, that colic could well be overlooked in hospital. Levin (1950) alone wrote that colic occurs in hospital, and described eight cases which he had seen. He thought that the idea that colic does not occur in hospital can be explained by the failure of the nurses and doctors to recognize it.

The most popular explanation of colic is excess of wind in the bowel, or wind trapped in a loop of bowel. Most workers ascribe the excess of wind in the bowel to swallowing air. Several workers mention the relief given by the passage of flatus, placing the baby in the prone position, or applying pressure to the abdomen. Several others ascribe colic to spasms of the intestine, mostly in association with excess of wind (Keiter, 1938; Miller, 1948; White, 1929; Bonar, 1935). White terms the condition 'vagogenic gastroenterospasm'. Some workers ascribe it somehow to immaturity of the intestine, with imbalance of the autonomic nervous system. Jorup (1952) in careful radiological studies found that there was no excess of wind in the intestine, but that the colon showed excessive propulsive activity. He was impressed by the forceful expulsion of barium given as an enema. He found that attacks of pain corresponded in time with violent contractions of the colon.

Finally, a wide variety of other causes have been given for colic in the young baby. They include congenital malformations of the alimentary tract, inguinal hernia, urethral colic, appendicitis, foreign bodies in the alimentary tract, lead poisoning, anal fissure, imperforate anus, peptic ulcer, 'disease of the gall bladder, respiratory tract or osseous system', congenital syphilis, volvulus, intussusception, renal colic, nasopharyngitis, otitis, pyelitis, 'tension developed in utero from a hypothetical uterine handicap or transmitted from a high strung mother's system', hyperacidity, exposure to cold, chilling of the extremities, abdominal binders, fatigue toxins from the mother, tension due to lack of oral satisfaction, acidosis, introversion and accumulation of uric acid in the kidneys.

Suggested lines of treatment naturally reflect the views as to the aetiology. They are outlined here for that reason, and because they throw further light on the opinions as to the cause of colic. Moore (1942), Neff (1940) and others advise that the baby should not be picked up so much, and that he should be handled slowly and gently. Spock (1944) warns that it is useless to change the feed, but numerous workers advocate changes in the frequency, quantity and constitution of the feeds. The changes recommended include an increase or decrease in their frequency, increased or decreased quantities, changes in the protein, fat or carbohydrate content, the use of protein milk, buttermilk, skimmed or evaporated milk, lactic acid milk, removal of the baby from the breast, removal of various substances from the mother's diet, the substitution of banana powder for other sugars, the giving of a warm cereal gruel before feeds, thickening the feeds with cereal and adding barley water or casein derivatives to the feed. McGee (1950) suggests a whole series of changes, each one to be tried for a time: boiling the milk, changing to one of low fat content, giving goat's milk, mull-soy, nutramigen, and finally strained meats, olive oil, sugar and calcium instead of milk. One feels that as colic is a self-limiting disease most babies would be better before all these had been tried.

Many workers advocate the use of atropine, some of them until flushing occurs, and other antispasmodics. Levy and Zweifler (1952) found banthine bromide effective. Jorup (1952) found that methylscopolamine nitrate ('skopyl') relieved the symptoms in all his cases. Others recommend prostigmine, opium derivatives, 'demerol,' phenobarbitone, chloral, sodium bicarbonate, peppermint water, sodamint, tincture of cardamom, magnesium carbonate, 'dill water', bismuth, sal volatile, sulphocarbolate of soda, creosote, papain, nux vomica, salad oil, calcium chloride, calcium gluconate or potassium citrate. McGee (1950) found that a drink of whisky (taken by the baby) was effective. Grulee (1920) suggested that every morning and evening the baby should be given $5 \mathrm{ml}$. of a liquid culture of active lactic acid bacilli.

Numerous workers (e.g., Brennemann, 1948; Higgins, 1942; Miller, 1948) found that an enema gave prompt relief in attacks. Keiter (1938) recommends that a glycerine suppository should be held in place for 10 minutes before feeds. Others advocate the use of a rectal tube. Another worker recommends dilatation of the anal sphincter. Many workers recommend that all precautions should be taken to reduce swallowing air. Levine and Bell (1950) advocate the use of a dummy or pacifier.

As for the prognosis, only two writers (Sheldon, 1951; Still, 1927) suggest that there is any danger in colic: they wrote that it may lead to convulsions. Spock (1949) rightly points out that a baby with colic may become so used to being picked up because of pain in the evenings that he develops a habit of expecting to be picked up: crying in the 
evenings therefore persists long after all pain has stopped. McGee (1950) states that throughout life many of these children are poor vegetable eaters, and are finicky with their food. When they begin to go to the kindergarten they will miss a lot of school because of colds, bronchitis, nausea, vomiting, abdominal pain, headaches or fatigue. At school he says that they have difficulty in keeping quiet and in paying attention, and are apt to molest other children. He gives no evidence for these statements. Jorup (1952) says that they later prove to be difficult to wean. They are afraid of strangers. They suck their thumbs or bite their nails. They have a tendency to diarrhoea or to spasms of colic. He did not, however, study controls in whom the incidence of those complaints could be compared.

Such is the literature about colic. The clinical descriptions given by Spock (1946) and Brennemann (1948) are excellent, but I have found no paper which compares colicky babies with others, or which describes a controlled investigation of its treatment. The paper by Jorup (1952) is the only one which really studies colic in some detail, and which has included radiological examination, but, as stated above, the babies which he described had symptoms and signs which are different from those described in this paper.

\section{The Present Study}

Method. Data were collected about 50 consecutive babies in the first three months of their life who were said by their mothers to have violent, rhythmical, screaming attacks which did not stop when they were picked up, and for which no cause, such as underfeeding, could be found. Mild cases were excluded, because of the ease with which a wrong diagnosis can be made. The babies were seen in the follow-up clinic for well babies at the Jessop Hospital for Women, Sheffield. Almost all babies are first seen in this clinic between the age of 15 and 30 days. In all cases the diagnosis was made at the time of the first attendance. Three or four babies originally included in the investigation were subsequently withdrawn, because their subsequent course suggested that there were causes other than colic which were responsible for the screaming attacks. In the great majority of cases the mother complained spontaneously about the attacks, but in a few the diagnosis was established as a result of the direct questions, 'How does he behave during the day?', 'What is he like at night?' Apart from the question, 'At what time do the attacks occur?' there were no other leading questions.

When a baby who satisfied the above criteria for diagnosis was found, a pro forma was filled in, on which numerous details of the baby, his mother, the feeding methods and other relevant data were recorded. A routine examination was performed, including a simple developmental examination, on the lines of that suggested by Arnold Gesell.

For comparison controls were chosen in the following way. Whenever a baby was found to have colic, the next baby seen, provided that he had no colic or excessive crying, was used as a control, and a control pro forma was filled in. If two consecutive babies had colic, the next two symptomfree babies were used as controls. In a sense, therefore, both groups were selected, but they were only selected on the grounds of having definite colic of quite severe degree, or of having no colic or anything like it. In all other senses they were unselected and therefore strictly comparable. It should be pointed out, however, that the babies seen at the Jessop Hospital are not representative of the general population, in that the mothers are usually primiparae or have some complication of pregnancy.

It is unfortunate that one has to rely largely on the mother's story for a study of this nature. One is not justified in admitting babies (with their mothers) to hospital for evening colic because the condition is a self-limiting one, because of the risk of infection, and for domestic reasons. It was difficult to obtain x-ray studies, because it was felt that x-ray examination should only be done at the time of the colic, and this necessitated evening visits, often from a considerable distance. $\mathrm{X}$-ray studies were carried out in the evenings, however, on seven severe cases, thanks to the cooperation of the mothers, the radiologists and the radiographers. These radiographs were taken during the attacks of colic. Straight radiographs were followed by a barium enema.

For the purposes of assessment of the straight radiograph a radiographer was asked to pick out at random radiographs of seven babies under 3 months of age, taken for non-abdominal conditions (mostly upper respiratory tract infections), and which included the abdomen on the x-ray film. The radiographs of the babies with colic were then mixed with these. A radiologist (Dr. T. Lodge) then examined the films without knowing the names or condition from which they were suffering and graded them according to the amount of gas in the intestine.

All babies were seen by me personally, and followed up by me, as far as possible up to the age of 6 months. There were 50 babies in each series, and they were seen in the course of one year. 
Results. Table 1 shows that there was no significant difference between the two groups with regard to the age of the mother, her parity, the incidence of illnesses during pregnancy, the incidence of foetal 'hiccoughs', the family history of allergy, the sex or birth weight of the baby, the number of feeds per day or the incidence of posseting or vomiting. Slightly more babies in the colic group

TABLE 1

COMPARATIVE DATA ON MOTHER AND CHILD

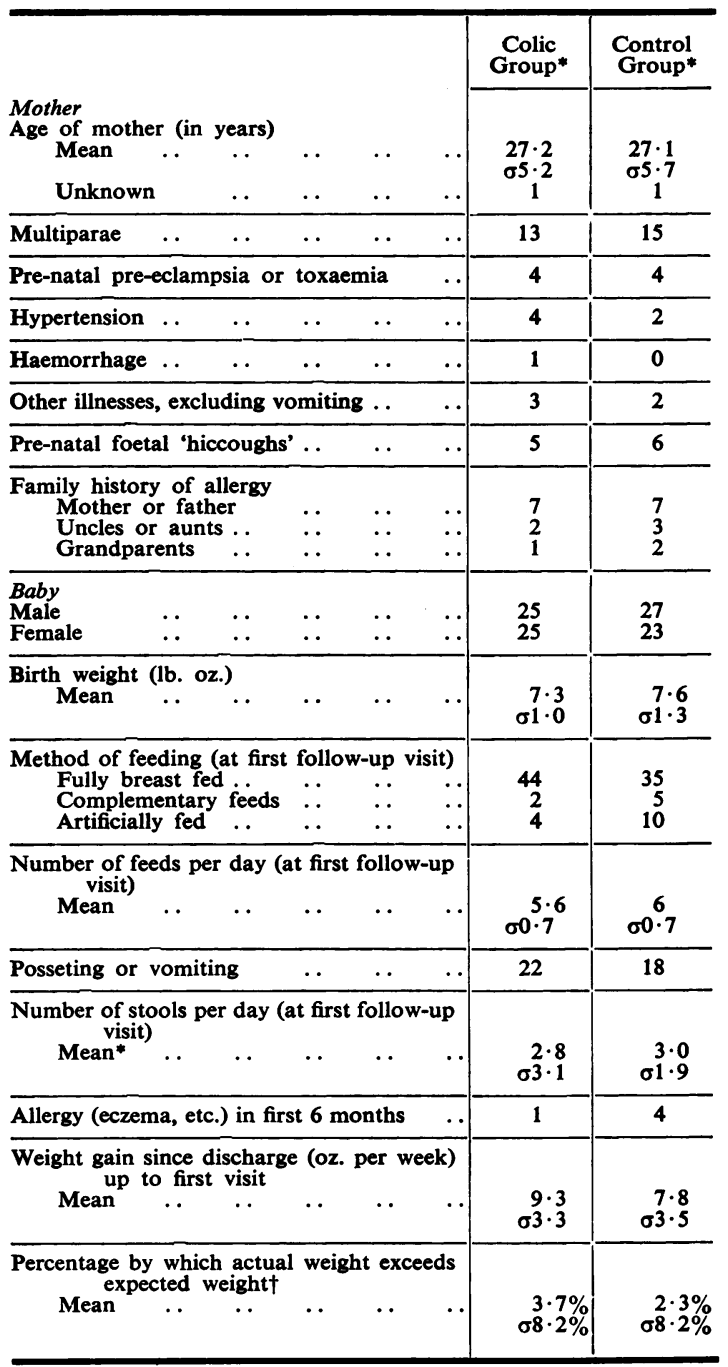

* Fifty cases in each group. No record in one colic case.

$t$ The expected weight was obtained by adding $1 \mathrm{oz}$. for each day of life to the birth weight and subtracting 10 .
(44 out of 50) were fully breast fed when first seen, as compared with the control group (35 out of 50). This probably explains the fact that 13 of the babies in the colic group had a motion less frequently than once a day, as compared with five in the control group, for many breast-fed babies have infrequent motions. There was no suggestion of diarrhoea in any of the colic group, which is interesting in view of the often repeated statement that all or most of the babies with colic have diarrhoea.

One child with colic developed mild eczema compared with four in the control group. This figure is not accurate, for not all babies were followed up until 6 months. There was certainly no greater incidence of eczema or other allergic conditions in the babies with colic.

The weight gain between the time of discharge from hospital and the first attendance in the followup clinic averaged $9 \cdot 3 \mathrm{oz}$. per week in the colic group and $7.7 \mathrm{oz}$. in the control group. Nineteen babies in the colic group and 19 in the control group were $5 \%$ or more above the expected weight when first seen in the follow-up clinic. Thirty-five babies in the colic group and 32 in the control group were up to the expected weight. Six babies in the colic group and nine in the control group were $5 \%$ or more below the expected weight.

Table 2 gives further data about the babies with colic. In 33 of the babies the colic developed in the first 10 days during the stay in hospital. In 44 babies it developed in the first $\mathbf{1 5}$ days. In no case did a child develop colic after being seen on the first visit in the follow-up clinic. In those who had

TABLE 2

DATA CONCERNING COLIC

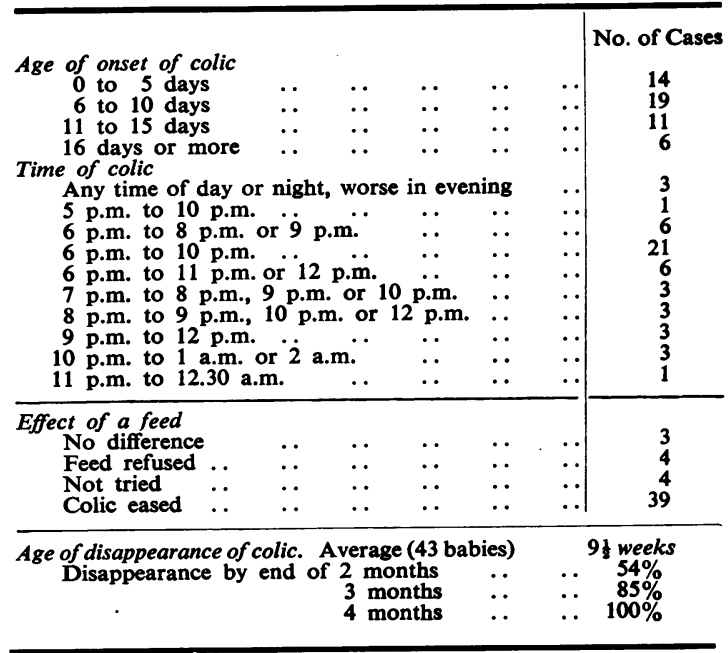


not had colic while in hospital, symptoms developed within a week of going home.

In all cases the colic occurred in the evening, but in eight cases it occurred at other times as well, although in them the symptoms were much worse in the evening. In five of them symptoms occurred at other times of the day only on odd occasions. The time of onset of the colic is interesting (Table 2). In 47 of the 50 babies it began at 5 p.m. or later, usually $6 \mathrm{p} . \mathrm{m}$. These times refer to the time of onset as given by the mother at her first attendance in the follow-up clinic. In a few cases the time of onset shifted as the baby grew older. The duration of the colic, with the exception of those three who had colic earlier in the day as well, averaged 3.7 hours when the baby was first seen: the range was one to six hours.

In 39 babies the colic was eased by a feed, in almost all cases only for a short time (10 to 30 minutes). Four babies refused feeds when suffering from colic; three were not helped; in the remaining four feeds were not offered at the time.

The average age at which the symptoms of colic disappeared was $9 \frac{1}{2}$ weeks. Approximately two out of five babies lost the colic by the age of 8 weeks, four out of five by the age of 12 weeks, and all had lost it by 16 weeks.

$\mathrm{X}$-ray studies were carried out on too small a number of babies for any firm conclusions to be drawn. Five of the seven babies with colic and one control baby were regarded as having a normal intestinal gas content: two babies with colic and three controls showed a slight increase of gas ('Grade I'). None of the colic babies but three of the controls showed a large amount of gas ('Grades 2 and 3'). All we can say with certainty was that in those seven babies with colic at the time of the $\mathrm{x}$-ray studies there was no evidence of excess of gas in the intestine.

Barium enemas gave no definite information. In three of the children the radiograph showed a loop of redundant sigmoid curling over into the right iliac fossa, but this is known to be common in normal babies at this age. This matter is being investigated further. It is true that the barium was not well retained, as Jorup (1952) found, but we did not feel that the babies with colic were different in this respect from other babies. It was not possible to demonstrate any local obstruction to the passage of gas, but it is possible that further studies will throw light on this.

The Causes of Crying and Colic

One gains the impression from many papers that colic is regarded as practically synonymous with crying. It is very common, however, to see screaming attacks in the evenings in young babies, without any of the known causes of crying being discoverable. The screams are those of pain; they do not stop when the child is picked up; they are rhythmical, suggesting an intestinal origin; they are not due to hunger. This is the picture of the severe case of colic, and nothing can really be confused with it. The mild form, however, can be indistinguishable from other causes of crying, and any diagnosis of colic can be only a matter of opinion: it can only be made in those cases by excluding other causes, by giving, for instance, extra feeds in the evening in order to make sure that the crying is not due to hunger.

\section{Principal Suggested Causes of Colic}

Underfeeding. The effects of underfeeding may be indistinguishable from mild colic, except by the relief of symptoms when the underfeeding is corrected. The crying of hunger, like that of colic, is not relieved by picking the baby up: the baby obtains relief, like the colicky baby, by sucking; and in the case of the breast-fed baby the hunger may be only in the evening, for it is common for the milk supply to fall off in the late afternoon and early evening, being perfectly adequate at other times of the day. Not even an average weight gain excludes the possibility of hunger, for there may be sufficient milk in the rest of the day to ensure an average weight gain. But an average weight gain is not necessarily an optimum one for the child in question. When a baby is gaining $12 \mathrm{oz}$. a week, he is likely to cry a great deal if his feeds are cut down so that his weight gain is merely average. A further snare in the diagnosis lies in infrequent visits. When a baby, for instance, who is seen after an interval of three weeks has gained $21 \mathrm{oz}$. in that period, it is impossible to be sure that the weight gain has been uniformly distributed within that period: he may have gained $9 \mathrm{oz}$. in each of the first two weeks and only $3 \mathrm{oz}$. in the third week. Of course if the weight gain is better than the average it is extremely unlikely that hunger is the cause of crying. It should be noted, however, that the crying of hunger is different from the high-pitched scream of pain. When in doubt test feeding should be carried out in the breast-fed baby, and in case of need a complementary feed, or in a bottle-fed baby, a bigger feed should be given to determine whether it will relieve the symptoms.

I feel that the results of this study show conclusively that colic in our cases was not due to underfeeding. The weight gain in 49 of the 50 cases had been over $5 \mathrm{oz}$. per week in the interval between 
discharge and the first attendance at the hospitalat a time when colic was severe: in 35 of the 50 the weekly weight gain was over $7 \mathrm{oz}$. and in 19 over $10 \mathrm{oz}$. Thirty-five of the babies were above the expected weight when first seen. More important still, the weight gain was on the whole greater in the colic series than in the control group.

In eight of the babies who started to have colic in the first week while still in hospital, test feeds were carried out on the seventh day, and in all cases the results indicated an intake of milk which seemed adequate in relation to the weight. The average quantity of milk obtained in the evening feed at the time of colic was $3 \cdot 1 \mathrm{oz}$. Test feeds were carried out in four older babies who had colic, and in all of them the quantity obtained in the evenings seemed to be satisfactory.

In all children in whom the weight gain was defective, the food intake was increased. In those who were fully breast fed, this was achieved by expressing milk after every feed, in order to empty the breast better and so to stimulate milk production, and if this failed, complementary feeds were given. Yet in none of the children who were given complementary feeds in this way, and in none of the five who were changed entirely on to artificial feeds, was the colic in any way affected in spite of a considerable increase in the weight gain. The mothers of 10 babies took it on themselves to offer a bottle during the attacks of screaming: four of the babies refused to take the feeds, none of the other six were eased by the additional feed, and after two or three attempts the bottle was not offered again. It was striking that in nine babies in the control series in whom the weekly weight gain by the time of the first attendance had been below $5 \mathrm{oz}$., there had been no complaint of crying. In some of these children the weight gain had been grossly defective, in three being less than 2 oz. per week. It is a well known fact that underfeeding is by no means always accompanied by excessive crying. It is obvious that underfeeding, at least without some additional factor, does not cause evening colic.

Overfeeding. I firmly believe that for practical purposes overfeeding in a young baby is a myth. It is so rare that one can truthfully say that it practically never occurs.

It is true that the average weight gain in the colic series tended to be very slightly more than that in the control series, but the difference was not of statistical significance. Twelve of the controls were gaining more than $10 \mathrm{oz}$. a week, and yet did not have colic. Furthermore in 16 of the colic babies in whom the weight gain by the time of the first attendance had been much above the average, the weight gain rapidly fell in the ensuing four weeks without alleviation of the colic.

The number of feeds per day was almost exactly the same in the two groups.

Allergy. Our data give no support to the theory that the cause of colic is allergy. There was a family history of allergy in 10 babies in the colic group and in 12 in the control group. One baby in the colic group developed eczema compared with four in the control group. As for McGee's theory concerning foetal hiccough, five mothers of the colic babies gave a history of sudden, rhythmical, jerky movements in the foetus, simulating hiccoughs as compared with six mothers of babies in the control group. In the five babies who were taken off the breast because of insufficiency of milk and given cow's milk, the colic continued unabated not only when the breast milk supply fell off but when cow's milk was substituted.

All mothers who were breast feeding babies suffering from colic were asked whether any food which they were taking had a bearing on the colic. Only seven mothers answered in the affirmative, blaming grapefruit, tomatoes, sprouts, peas, beans, onions, turnips and bananas. Only one of those foods was blamed by two mothers, namely peas. It is doubtful whether any of them were really to blame, for the colic persisted even though these substances were excluded from the mother's diet.

Hypertonia. I was quite unable to find any of the so-called signs of hypertonia in the babies with colic. The muscle tone, head control and general development seemed to be identical in the two groups, both in the newborn period and when followed up to the age of 6 months. It is unfortunately not possible to translate these findings in the young baby into figures.

It was possible, however, to compare numerically the incidence of posseting or vomiting and the frequency of stools in the two groups. There was no significant difference. I have never seen 'diarrhoea' in a baby with colic, though there is no reason why it should not occur as frequently in babies with colic as it does in other babies. I have seen no evidence of 'spastic constipation' in babies with colic. In fact I have never seen any abnormality of the bowels in these cases.

I have not seen any of the other signs of hypertonia mentioned by writers, except those which can only be regarded as normal, such as "vigorous crying when getting a bath'. 
Gastric or Colonic Flatulence. Gastric flatulence ('wind') may be due to sucking too long on the breast, gulping the milk down too quickly as a result of an unduly rapid flow of milk from the breast, or, if the baby is bottle fed, from having too small a hole in the teat, from allowing him to suck when the teat has become flat as a result of a vacuum, from failure to tilt the bottle sufficiently to keep the teat full of milk, or from allowing him to suck when the bottle has been emptied.

Although excess of wind in the stomach causes screams of pain during or immediately after a feed, it does not cause rhythmical attacks of crying for several hours, which are not relieved by picking the baby up. If a baby with wind is picked up, the wind is likely to be expelled and the pain relieved.

The possibility that 'colic' is due to the passage of swallowed wind into the intestine is not so easy to discard. It is commonly supposed that most wind in the bowel is the product of fermentation and bacterial action, but it is difficult to say how much wind comes from the stomach. I do not think that adult air swallowers have an excess of wind in the bowel. It is well known that babies swallow air as a result of the various errors of feeding technique which have been mentioned, but I have not seen evening colic occur in such babies. The limited number of $\mathrm{x}$-ray studies which we were able to make in our cases did not show any excess of gas in the intestine, and that was the finding of Jorup (1952). There is therefore no evidence of excess of wind in the intestine of colicky babies.

That wind in the colon plays a part in the production of symptoms is strongly supported by the fact that attacks of colic are nearly always relieved by the passage of flatus or a stool. I have repeatedly observed attacks relieved in this way. Many workers, furthermore, have found that attacks are relieved by enemas. It would seem that an additional factor is necessary, probably of the nature of spasmodic contractions or kinking of the bowel. This is supported by the observation by myself and by many mothers that during an attack borborygmi are particularly noticeable. Mothers say that they hear the wind rumbling round.

It would seem doubtful whether immaturity of the autonomic nervous system is a factor, for one would expect that if that were the case colic would be commoner in premature babies, which it is not. (Three babies in the colic group and four in the control group were born prematurely. The incidence of premature births in the Jessop Hospital is approximately $8 \%$.) Pierce (1948) made the interesting observation that colic may begin later in premature babies than in full-term ones. I have seen this once only (in a baby seen after this series was completed). Confirmation of this is required.

Spoiling. One of the arguments adduced by several workers who ascribe colic to 'spoiling' is the statement that colic only begins when the mother gets home, and finds herself on her own without the moral support of the hospital staff. But in 33 out of 49 of our cases the colic began while the mother and baby were in hospital. It should be noted that at the Jessop Hospital babies are kept at the mother's bedside and can be picked up by the mother as often as she wants, and they are fed on a self-demand schedule. Some would call this 'over-permissiveness', but this is a matter of opinion. We commonly diagnose colic in babies during their stay in the Jessop Hospital, confirming the diagnosis by their subsequent course.

Analysis of other data, such as the age of the mother and her parity, which might have an indirect bearing on her liability to spoil her child, threw no light on the problem, for the data for the two groups were the same. Though only one child in a family may be spoiled, it was noted that not all children in a family suffered from colic, there being a history of colic in another sibling in three of the 11 babies in the colic series, who were not first born. No siblings of the 15 comparable babies in the control group had colic.

It is difficult to understand why rhythmical attacks of screaming, which do not stop when the baby is picked up and such as only occur with pain, should be ascribed to 'over-permissiveness' on the part of the mother, spoiling and other forms of mismanagement, yet many writers consider this to be an important cause of colic. Any parent who has possessed a child with colic knows that it is a most worrying and disturbing complaint, and that a baby with obvious pain has to be picked up and cuddled. Only a thoroughly hard-hearted mother, or a mother who has been foolish enough to listen to advice that a baby should never be picked up when he cries because of the risk of spoiling him, would leave him to cry without picking him up. As Spock (1949) pointed out, a baby may come to expect to be picked up in the evenings as a result of what has happened when he had pain, and the attacks of colic are then slowly and imperceptibly replaced by crying from habit. It is difficult to say where one ends and the other begins. The mother has to be guided by the nature of the cry, together with the fact that it is most unusual for true colic to continue after $3 \frac{1}{2}$ or 4 months. This spoiling is the result, not the cause, of the colic.

Though severe attacks of colic could hardly be 
mistaken for the mere desire to be picked up and loved, mild attacks could very well be so mistaken. It is quite possible, and indeed likely, on the one hand, that very mild discomfort in the evening would be enough to awaken a baby or keep him awake, but not enough to cause him to cry when in his mother's arms. On the other hand, it is common for young babies to sleep well during the day and night, but to regard the evening as a time for play. They are most wide awake then, and demand attention. Such babies are apt to be called naughty or spoiled but in fact they merely want love and attention, having been asleep all day. Mothers who rightly pick such babies up and play with them are apt to be considered to be overanxious or to be mismanaging them. This rhythm of evening activity is only temporary.

An intelligent older baby, from 2 months onwards, frequently cries from boredom, or from the desire for company. Such babies cry if left alone, but are perfectly content when in the presence of others and able to see what is going on without being picked up or being given attention. Ignorance of this fact leads many mothers to think that their baby has wind or colic, when in fact all he wants is to see what is happening. No baby with anything but the mildest colic would stop crying merely by being brought into the presence of others.

Desire for More Sucking Experience. There is no doubt that babies with colic are eased when they suck, and for that reason many babies with colic are given almost continuous breast feeds in the evenings. One mother said, 'She always seems to want feeding in the attacks, but when given the breast she doesn't take it: she just seems to want something in the mouth.'

Many mothers have told me how sucking seemed to afford some relief, and I have seen this myself. Levine and Bell (1950) for this reason advocated the use of a dummy or pacifier for babies with colic. The fact that sucking causes relief, however, does not prove that the cause can be found in a desire for further sucking experience.

We observed one baby with colic when under the $x$-ray screen, and could not detect any change in the gas pattern in the bowel when sucking was allowed. It is difficult to understand why babies obtain relief in this way.

Organic Causes. Though several writers have suggested that colic may be due to organic disease, especially intestinal obstruction, it is difficult to see how these conditions may be confused, except perhaps on the first day on which the colic occurs.
The regular attacks of pain every evening could hardly be due to obstruction.

Other Causes of Crying. There are many other causes of crying in young babies which can well be confused with colic. If a baby cries when returned to his cot after a feed, he is apt to be thought to have colic, though this crying may be due to wind or other causes.

A baby may feel hungry when he brings his wind up after a feed, and demand more milk. He may awaken and cry for food an hour or two after a feed even though there is enough breast milk if he is caused to suck longer than he needs on the first breast before being transferred to the second, for that will make him tired and he will go to sleep before he has had enough milk from the second breast. He goes to sleep, in other words, because he is tired, and not because he has had sufficient milk to put him to sleep. A baby may cry after a feed because he does not want to leave his mother's arms, because the light is put out, because he has wetted or soiled his napkin, or because he is uncomfortable from overclothing. Most babies cry when they are tired. All these causes of crying have to be eliminated before the diagnosis of colic can be made.

Purgatives Taken by the Mother. It has been suggested that colic in breast-fed babies is the result of constipation. There is disagreement (Illingworth, 1953) as to whether purgatives of the anthracine group (senna, cascara, rhubarb and aloes) can affect the baby, but some consider that they may. However only four of the 50 mothers of colicky babies were taking these purgatives, as compared with three in the control group.

\section{Discussion}

I believe that there is strong evidence that colic is not caused by underfeeding, overfeeding, errors of feeding technique, mismanagement, allergy, substances taken by the mother or swallowing air. I do not think that it is due to an excess of wind in the intestines. I have never seen any evidence that colic is associated with hypertonicity or with any particular type of baby or parent. The outstanding impression given by the colicky baby, except in the evening, is that he is a well, happy, thriving, well fed and well managed baby with nothing wrong with him. His stools are normal; he may posset, but he does not posset more than any other baby. He grows up to be a nice normal child in no way different from other children.

The most likely explanation of the attacks lies in a localized obstruction to the passage of gas in the colon by spasm or kinking of uncertain cause. This 
explanation alone explains the excessive borborygmi, the relief by the passage of flatus or of a stool, the relief by an enema, together with the absence of radiological evidence of an excess of gas in the bowel. The rhythmical attacks of abdominal pain at constant short intervals is typical of a pain of intestinal origin. It seems that the main hope of elucidating the cause of colic lies in further radiological studies of babies-both of sufferers and non-sufferers. Such studies are in progress, and it is hoped that they will form the subject of a further communication.

Further light may also be thrown on the condition by a study of the response to antispasmodic drugs; a controlled investigation into the effect of methylscopolamine nitrate is in progress at the Jessop Hospital.

I cannot suggest any reason for the predominant occurrence of colic in the evenings.

\section{Summary}

The term 'three months' colic' is reserved for a clinical entity in which the baby, in the first three months of life, has rhythmical screaming attacks in the evenings, which are not stopped when he is picked up, and for which there is no obvious explanation, such as hunger. The great ease with which crying can be ascribed to colic when in fact it is due to some readily correctable cause such as hunger is emphasized. Severe forms, however, are felt to be so characteristic that they cannot be confused with anything else. The literature on the subject is reviewed.

A controlled investigation of colic was carried out, 50 babies with colic being compared with 50 who had no colic. It is shown that the mothers of these two groups of babies differed in no way as regards their age, parity or pregnancy history. The babies differed in no way as regards their sex, birth weight, feeding history, family history of allergy, signs of allergy, incidence of posseting, number of stools, or weight gain. They appeared to be well, normal babies apart from their attacks of pain in the evenings, and when followed up they continued to be normal.

In 33 out of 49 babies the colic began in hospital. In 44 of the babies it began in the first 15 days. In 47 of the 50 babies it began at 5 p.m. or later in the evening. The average age at which the colic disappeared was $9 \frac{1}{2}$ weeks. Fifty-four per cent had lost it by the end of two months, $85 \%$ by the end of three months, and all by the end of four months.

The cause of colic, in the light of the above findings, is discussed. It is felt that it is not due to underfeeding, overfeeding, or other errors of feeding technique. It is not due to mismanagement or spoiling, to allergy, hypertonia, swallowed air or to foods taken by the mother.

$\mathrm{X}$-ray studies taken during an attack of colic did not show an excess of gas in the bowel. The most likely explanation of colic is thought to be the local obstruction to the passage of gas in the colon by local spasm or kinking of uncertain cause.

I wish to thank Dr. T. Colver, paediatrician, for permission to see some of his cases, and Drs. O'Donohoe, Kilpatrick and Barlow, paediatric registrars at the Jessop Hospital, for referring cases to me. My thanks are also due to the radiologists, Drs. Grout, Wilkie and L.odge, and the radiographers for the $\mathrm{x}$-ray studies. My thanks are due to G. H. Jowett, B.A., and W. M. Gibson, B.A., of the Department of Mathematics, for statistical assistance in the construction of Table 1.

BiBLIOGRAPHY

Alarcon, A. G. Quoted by Spitz, R. A. (1951). Psychoanal. Study Child, 6,255 .

Barnett, E. J. (1930). Arch. Pediat., 47, 452.

Bonar, B. E. (1935). J. Pediat., 7, 111 .

Brennemann, J. (1945). J. Amer. med. Ass., 127, 691.

-_- (1948). Practice of Pediatrics, vol. 1, ch. 25, p. 28 . Hagerstown, Maryland.

Copeland, E. P. (1940). J. Pediat., 16, 125.

Current, E. H. (1920). Northw. med., Seattle, 19, 259.

Donnally, H. H. (1930). J. Immunol., 19, 15.

Ellis, R. W. B. (1951). Disease in Infancy and Childhood. Edinburgh. Fanconi, G. and Wallgren, A. (1952). Textbook of Pediatrics. London.

Grulee, C. G. (1920). J. Amer. med. Ass., 75, 1701.

and Eley, R. C. (1948). The Child in Health and Disease. Baltimore.

Haas, S. V. (1918). Amer. J. Dis. Child., 15, 323.

Hess, J. H. (1940). J. Pediat., 16, 120

Higgins, J. M. (1942). Penn. med. J., 45, 455.

Holt, L. E. and McIntosh, R. (1953). Pediatrics, 12th ed., p. 273. New York.

Huenekens, E. J. (1928). J. Amer. med. Ass., 91, 1850.

Illingworth, R. S. (1953). Practitioner, 171, 533 .

Jorup, S. (1952). Acta paediat., Uppsala, Suppl. 85.

Jorup, S. (1952). Acta paediat., Uppsala, Sup.

Keiter, W. E. (1938). Va med. Mon., 65, 479.

Levin, H. (1950). Amer. J. Dis. Child., 79, 666. $37,750$.

Levy, H. and Zweifler, B. M. (1952). I Ibid., 40, 570 .

Lippman, H. S. (1928). J. Amer. med. Ass., 91, 1848.

McCleave, T. C. (1928). Ibid., 91, 1850 .

McGee, W. A. (1943). Sth. med. J., Bgham, Ala., 36, 508.

McGee, (1950). Ibid., 43, 335.

Maitland-Jones, A. G. and Wilmers, M. J. (1947). In Garrod, Batten and Thursfield's Diseases of Children, 4th ed., ed. Paterson, D. and Moncrieff, A. Vol. 1, ch. 17. London.

Miller, R. (1948). J. Indiana med. Ass., 41, 806.

Moncrieff, A. and Evans, P. (1953). Garrod, Batten and Thursfield's Diseases of Children, 5 th ed. London.

Moore, C. (1942). Neb. St. med. J., 27, 353 .

Neff, F. C. (1940). J. Amer. med. Ass., 114, 1745.

Nelson, W. (1950). Mitchell-Nelson Textbook of Pediatrics, p. 147. Philadelphia.

Pierce, P. P. (1948). Amer. J. Dis. Child., 75, 190.

Platou, E. S. (1927). Arch. Pediat., 44, 458.

Reilly, J. V. (1921). Neb. St. med. J., 6, 195.

Rosamond, E. (1921). Sth. med. J., Bgham, Ala., 14, 768.

Scott, A. J. (1931). Calif. west. Med., 35, 107.

Shannon, W. R. (1921a). Amer. J. Dis. Child., 22, 223.

Shannon, W. R. (1921a). Amer. J. Dis.

Sheldon, W. (1951). Diseases of Infancy and Childhood, 6th ed. London.

Snow, W. (1937). Amer. J. Roentgenol., 38, 779.

Soto, R. (1937). Quoted by Spitz, R. A. (1951).

Spitz, R. A. (1951). Psychoanal. Study Child, 6, 255.

Spock, B. (1944). Psychosom. Med., 6, 162. (1946).

York.
(1949). Pediatrics, 4, 89.

Still, G. F. (1927). Common Disorders and Diseases of Childhood, 5 th ed., p. 151. London.

White, P. J. (1929). Amer. J. Dis. Child., 38, 935

- (1936). Med. clin. N. Amer., 20, 511. 